\title{
Efeitos dos sistemas de manejo sobre o carbono orgânico total e carbono residual de um latossolo vermelho eutroférrico
}

\section{Total organic and residual carbon contents of oxissol under diferents crop systems}

\author{
Cristine Elizabeth Alvarenga Carneiro ${ }^{1}$; Nagib Jorge Melém Júnior ${ }^{2}$; \\ Mateus Carvalho Basilio de Azevedo ${ }^{3}$; Elizete Anelli Andrade ${ }^{4}$; \\ Mirian Sei Koguishi ${ }^{4}$; Raquel Catia Diehl'; Wilian da Silva Ricce ${ }^{4}$; \\ Amarildo Luiz Passarin ${ }^{4}$; Ruy Hamilton de Mattos Vaz;
}

Tito Lívio da Luz Stelmachuk ${ }^{4}$; Maria de Fátima Guimarães ${ }^{5}$; Ricardo Ralisch ${ }^{5 *}$

\section{Resumo}

A degradação dos solos é atribuída à utilização de sistemas de manejo inadequados, do qual resulta a diminuição da matéria orgânica, da fertilidade química e de atributos físicos. O plantio direto é eficaz na proteção da superfície do solo devido à deposição dos resíduos culturais. Este trabalho teve por objetivo avaliar o carbono orgânico total e residual de um Latossolo Vermelho eutroférrico sob os sistemas de manejo convencional, plantio direto e pasto, utilizando uma mata secundária em processo de regeneração como referência. Quanto menor a mobilização e maior a manutenção dos resíduos vegetais sobre o solo, maiores foram os teores de carbono orgânico total e de carbono residual.

Palavras-chave: Matéria orgânica, plantio direto, carbono orgânico

\begin{abstract}
The soil degradation is related to inadequate use of tillage systems, which result in decrease of organic matter content, chemical fertility and physical attributes. The no-tillage system is effective in protection of the soil surface. This study aimed to evaluate the carbon content of the oxissol under conventional tillage, no-tillage and pasture systems, using a secondary forest in regeneration as reference. As smaller the mobilization and larger the maintenance in soil of the vegetable residue, larger were the content of organic carbon and of residual carbon.
\end{abstract}

Key words: Organic matter, no-tillage, organic carbon

\footnotetext{
1 Programa de Pós-graduação em Agronomia da Universidade Estadual de Londrina - UEL - C.P. 6001, CEP.86.051-990, Londrina, PR. Tel. 43 3371-4555.

2 Programa de Pós-graduação em Agronomia da Universidade Estadual de Londrina - UEL - C.P. 6001, CEP.86.051-990, Londrina, PR. Tel. 43 3371-4555. Pesquisador da Embrapa Amapá.

3 Programa de Pós-graduação em Agronomia da Universidade Estadual de Londrina - UEL - C.P. 6001, CEP.86.051-990, Londrina, PR. Tel. 43 3371-4555. Professor do Departamento de Agronomia da UEL.

4 Programa de Pós-graduação em Agronomia da Universidade Estadual de Londrina - UEL - C.P. 6001, CEP.86.051-990, Londrina, PR. Tel. 43 3371-4555.

5 Professores do Departamento de Agronomia da UEL. E-mail: ralisch@uel.br

* Autor para correspondência
} 


\section{Introdução}

A exploração agrícola tem levado à degradação dos solos, com prejuízos ao desenvolvimento das plantas cultivadas devido à diminuição da matéria orgânica e da fertilidade. De acordo com Silva, Lemainski e Resck (1994), sistemas de manejo com intenso revolvimento do solo apresentam rápida queda da matéria orgânica, decorrente do aumento das perdas por erosão hídrica, oxidação microbiana e degradação da matéria húmica. A palhada na superfície do solo em plantio direto pode promover aumento dainfiltração edoarmazenamento deáguano solo, diminuição da temperatura superficial, redução do impacto da gota de chuva, aumento da atividade microbiana e acúmulo superficial de nutrientes e de matéria orgânica (BAYER; MIELNICZUK, 1999). A queima e/ou remoção de resíduos culturais reduzem o acréscimo anual de carbono orgânico total (COT) e residual. Culturas com sistema radicular abundante e agressivo, que alocam uma fração maior do carbono fotossintetizado para as raízes, podem ser mais eficientes em aumentar os estoques do COT do solo (SHAMOOT; MCDONALD; BARTHOLOMEW, 1968) e consequentemente aumentar o carbono residual. Assim, as frações de carbono podem contribuir diferentemente para a melhoria das propriedades químicas, físicas e biológicas. Desta forma o trabalho teve por objetivo avaliar o carbono orgânico total e residual de um Latossolo Vermelho Eutroférrico sob os sistemas de manejo convencional, plantio direto e pasto, utilizando uma mata secundária em processo de regeneração como referência.

\section{Material e Métodos}

Amostras de um Latossolo Vermelho eutroférrico (EMPRESA BRASILEIRA DE PESQUISA AGROPECUÁRIA - EMBRAPA, 1999) foram coletadas em maio de 2005, em áreas agrícolas em uso, localizadas em Bela Vista do Paraíso - PR
(22 $\left.2^{\circ} 59^{\prime} 48^{\prime \prime} \mathrm{S}, 51^{\circ} 11^{\prime} 26^{\prime \prime} \mathrm{W}\right)$. Os seguintes sistemas de manejo foram avaliados: (a) Sistema convencional, sendo realizado há 6 anos, constando de uma aração e uma gradagem no verão e uma escarificação no inverno com sucessão das culturas soja - milho com a manutenção dos resíduos sobre o solo e adubação com $300 \mathrm{~kg} \mathrm{ha}^{-1}$ de NPK na formulação 10-20-20 no sulco de plantio, (b) Sistema de plantio direto sendo realizado há 8 anos, com sucessão das culturas soja - milho e adubação com $300 \mathrm{~kg} \mathrm{ha}^{-1}$ de NPK na formulação 10-20-20, no sulco de plantio. As adubações foram realizadas com base em análise de solo anuais. (c) Uma área de pastagem (grama estrela) com 10 anos e (d) uma mata secundária em regeneração (sofreu um incêndio há 20 anos), com espécies nativas, exóticas e invasoras. Em uma área de 0,5 ha foram coletados os resíduos culturais dos sistemas convencional e de plantio direto, assim como a serrapilheira da mata, utilizando um quadro de $25 \times 25 \mathrm{~cm}$, com cinco amostragens ao acaso. Neste mesmo local, foram realizadas ao acaso 5 amostragens simples de solo, com o auxílio de uma pá reta, subdivididas nas profundidades $0-5,5-10$ e $10-20 \mathrm{~cm}$, totalizando 60 amostras, que foram secas ao ar e passadas em peneiras com malha de 2 $\mathrm{mm}$ de abertura. As análises químicas e de carbono orgânico total (método Walkley - Black, com o dicromato de potássio servindo como oxidante do carbono orgânico) foram realizadas de acordo com Pavan et al. (1992). O carbono residual (CR) foi quantificado pelo método Walkley - Black de acordo com Pavan et al. (1992), após a oxidação do carbono lábil com $\mathrm{KMnO}_{4}(33 \mathrm{mmol} \mathrm{L}-1)$, como proposto por Blair, Lefroy e Lisle (1995) e modificado por Shang e Tiessen (1997). Os resultados foram analisados como um delineamento casualizado com cinco repetições por profundidade, três repetições laboratoriais, sendo os dados submetidos à análise de variância e a comparação das médias feita pelo teste de Tukey a 5\% de significância, utilizando o programa estatístico SISVAR 4.6 (FERREIRA, 2003). 


\section{Resultados e Discussão}

$\mathrm{O} \mathrm{pH}$ apresentou-se mais alto na mata em todas as profundidades, o que é compatível com os baixos valores de $\mathrm{Al}$ e $\mathrm{H}+\mathrm{Al}$ (Tabela 1). Não se observou grande variação na $\mathrm{CTC}_{\mathrm{pH} 7}$ entre os sistemas, isto pode ser atribuído ao alto tamponamento do solo (argila $\left.=660 \mathrm{~g} \mathrm{~kg}^{-1}\right)$, o que provavelmente atenua o efeito dos sistemas. Ciotta (2001) somente verificou incremento significativo da $\mathrm{CTC}_{\mathrm{pH}}$, após 20 anos de utilização de um Latossolo Bruno. Foi observado deficiência de fósforo no sistema pastagem em todas as camadas devido a nãoreposição do elemento através da adubação mineral
(Tabela 1). Naturalmente este solo possui baixo teor de $\mathrm{P}$, devido ao material de origem (basalto) com baixos teores de $\mathrm{P}$ e elevados teores de materiais altamente adsorvedores, óxidos e hidróxidos de ferro e alumínio. A ciclagem de nutrientes revelase importante, pois, os teores de fósforo no solo da mata (Tabela 1) apresentaram uma tendência de serem mais elevados em todas as camadas quando comparado com a pastagem. Os teores homogêneos de $\mathrm{P}$ em profundidade, no sistema convencional, são devidos à mobilização e homogeneização das camadas analisadas. No sistema plantio direto observou-se a concentração do $\mathrm{P}$ na base do sulco de plantio, na camada $5-10 \mathrm{~cm}$.

Tabela 1. Características químicas das camadas para os sistemas de manejo em um Latossolo Vermelho Eutroférrico.

\begin{tabular}{|c|c|c|c|c|c|c|c|c|c|}
\hline \multirow{3}{*}{ Sistema de Manejo } & $\mathrm{pH}_{\mathrm{CaCl} 2}$ & $\mathrm{Al}$ & $\mathrm{H}+\mathrm{Al}$ & $\mathrm{Ca}$ & $\mathrm{Mg}$ & $\mathrm{K}$ & SB & $\mathrm{CTC}_{\mathrm{pH} 7}$ & $\mathrm{P}$ \\
\hline & & \multicolumn{7}{|c|}{ cmolc dm-3 de solo } & $\mathrm{mg} \mathrm{dm}-3^{\mathrm{dm}}$ \\
\hline & \multicolumn{9}{|c|}{ Camada $0-5$} \\
\hline Mata & 6,64 & 0,03 & 2,76 & 6,83 & 0,75 & 0,96 & 8,54 & 11,30 & 13,12 \\
\hline Convencional & 6,00 & 0,15 & 3,50 & 7,60 & 1,37 & 0,83 & 9,80 & 13,30 & 25,94 \\
\hline Plantio Direto & 5,94 & 0,09 & 3,39 & 6,48 & 1,65 & 1,26 & 9,39 & 12,78 & 6,60 \\
\hline \multirow[t]{2}{*}{ Pasto } & 5,54 & 0,07 & 4,29 & 8,17 & 1,43 & 2,01 & 11,61 & 15,90 & 3,48 \\
\hline & \multicolumn{9}{|c|}{ Camada $5-10$} \\
\hline Mata & 6,80 & 0,02 & 2,53 & 7,13 & 0,65 & 0,80 & 8,58 & 11,10 & 6,16 \\
\hline Convencional & 5,74 & 0,11 & 3,81 & 7,26 & 1,24 & 0,58 & 9,08 & 12,90 & 27,98 \\
\hline Plantio Direto & 5,42 & 0,09 & 4,45 & 5,97 & 1,27 & 0,78 & 8,02 & 12,47 & 22,78 \\
\hline \multirow[t]{2}{*}{ Pasto } & 5,52 & 0,09 & 3,99 & 7,83 & 1,24 & 1,66 & 10,73 & 14,72 & 1,98 \\
\hline & \multicolumn{9}{|c|}{ Camada $10-20$} \\
\hline Mata & 6,84 & 0,02 & 2,43 & 9,65 & 0,84 & 0,68 & 11,17 & 13,60 & 4,34 \\
\hline Convencional & 6,04 & 0,07 & 3,69 & 6,91 & 1,15 & 0,47 & 8,53 & 12,22 & 20,04 \\
\hline Plantio Direto & 5,08 & 0,10 & 4,31 & 5,27 & 0,88 & 0,36 & 6,51 & 10,82 & 5,50 \\
\hline Pasto & 5,30 & 0,09 & 4,88 & 7,91 & 1,13 & 1,17 & 10,21 & 15,09 & 2,08 \\
\hline
\end{tabular}

Os teores de carbono total entre sistemas e em profundidade, mostrados na Figura 1a, indicaram que a mata, apresentou o maior teor na profundidade de $0-5 \mathrm{~cm}$. Neste sistema, a matéria orgânica encontra-se preservada, devido a não mobilização do solo e a constante ciclagem do material vegetal, proporcionado pela maior diversidade de espécies presentes. Emborana pastagem não exista diversidade vegetal e a ciclagem seja bem menor do que na mata, o teor de carbono total nas profundidades 5-10 e 10-20 não diferiu da mata. A pastagem oferece uma cobertura permanente e uma alta distribuição radicular, minimizando os efeitos das intempéries climáticas, contribuindo para o aumento gradativo do 
carbono. Nos sistemas plantio direto e convencional não se observou diferenças até a profundidade de $10 \mathrm{~cm}$, isso porque, neste sistema convencional não se realiza mobilização constante, o que preserva em parte a palhada sobre o solo entre uma cultura e outra, favorecendo o acúmulo de carbono orgânico total. Entretanto, os resultados na profundidade de 10-20 mostram diferença entre os sistemas.

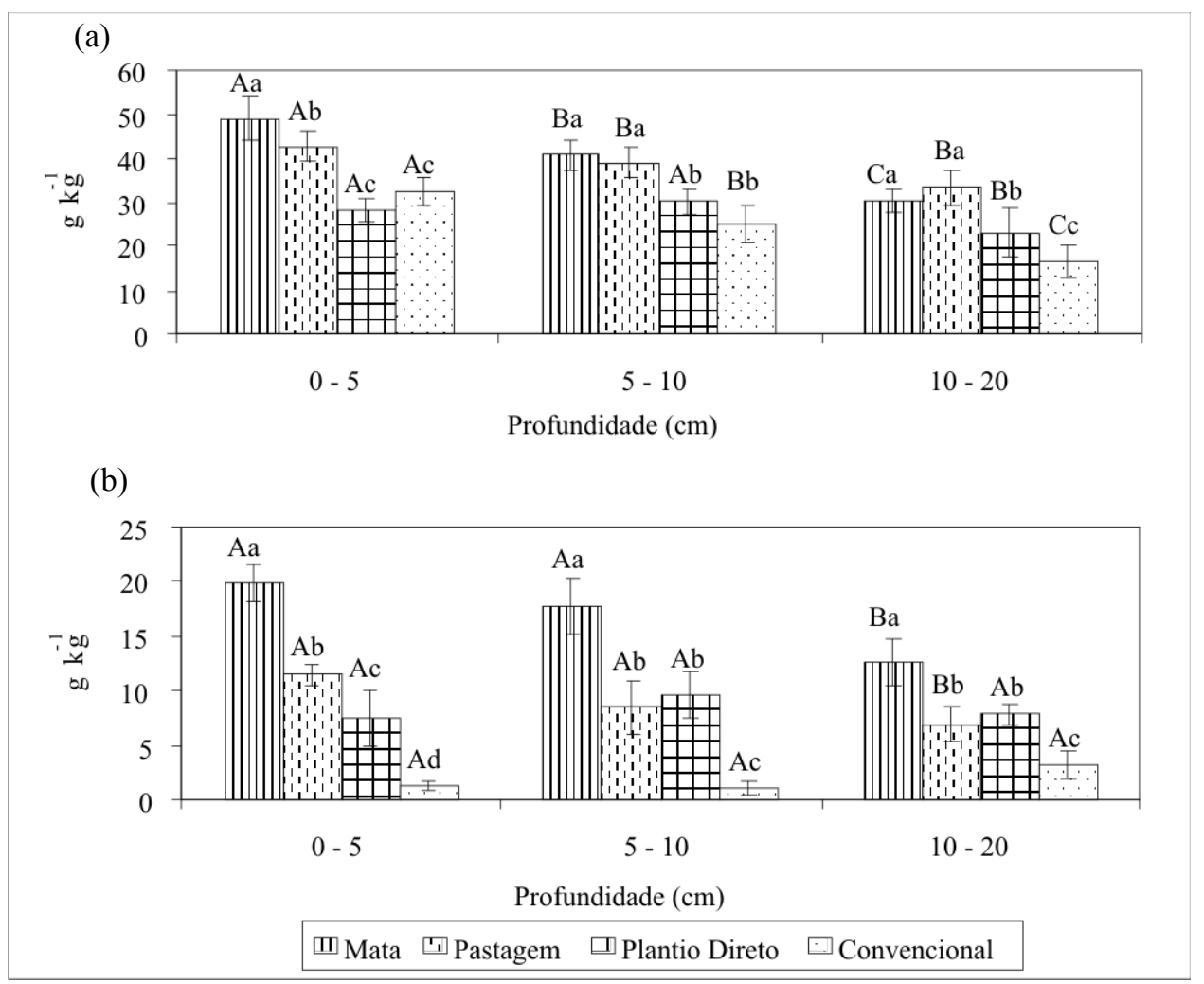

Figura 1. Teor de carbono orgânico total $\left(\mathrm{g} \mathrm{kg}^{-1}\right)$ (a) e teor de carbono residual $\left(\mathrm{g} \mathrm{kg}^{-1}\right)$ (b) em quatro sistemas de manejo. Mesmas letras maiúsculas não diferem entre si dentro do mesmo sistema, nas respectivas profundidades, e mesmas letras minúsculas não diferem entre si entre os sistemas para cada profundidade. (Teste de Tukey, $\mathrm{P} \leq 0,05$ ).

O plantio direto promoveu o aumento do estoque de carbono, o que não aconteceu no convencional. Pode-se inferir que no sistema convencional, devido à escarificação, ocorreu o revolvimento de parte dos restos vegetais e das raízes para a superfície, as quais participariam do aumento do estoque de carbono na profundidade de $10-20 \mathrm{~cm}$. Albuquerque et al. (2005) observaram o acúmulo de $\mathrm{CO}$ no preparo reduzido (PR), mas não no convencional (PC), ressaltam que, ao longo do tempo, o acúmulo de matéria orgânica no PR, comparado ao PC, será maior, com conseqüências positivas em outros atributos do solo.
A mata apresentou os maiores teores de CR e o sistema convencional os menores (Figura 1b). O carbono residual é o que confere maior estabilidade à matéria orgânica do solo, por estar na forma húmica e possibilitar a formação de agregrados, os quais preservam as características químicas e físicas do solo (BAYER; MIELNICZUK, 1999). Apesar do teor de COT no sistema convencional, devido a presença da palhada, este está passível de sofrer oxidação, ou seja, é composto de carbono lábil, conseqüentemente, poderá ser liberado na forma de $\mathrm{CO}_{2}$ para a atmosfera, após mineralização, contribuindo para o aumento de emissão de gases e 
redução da fertilidade do solo. No entanto, inferese que se este tipo de manejo tiver continuidade, o COT terá influência significativa no aumento do teor de CR (BAYER; MIELNICZUK, 1999). Já na mata, no plantio direto e na pastagem, a fração do CR é responsável pelos teores do COT. De acordo com Diekow et al. (2005) esta contribuição é devida a não destruição dos agregados do solo causada pelo preparo, o que expõe a matéria orgânica aos microorganismos e suas enzimas, cuja atividade encontra-se intensificada em função das condições mais oxidantes do ambiente. Conforme o manejo a matéria orgânica pode sofrer diferentes transformações, oxidação ou humificação, devido à influência climática, da reposição da matéria orgânica, da atividade microbiana e outros.

As quantidades dos resíduos vegetais do plantio direto não diferiram da serrapilheira, entretanto foram superiores aos resíduos do plantio convencional (Figura 2), denotando a importância do plantio direto no incremento gradativo da matéria orgânica e na proteção da superfície do solo. Já no sistema convencional, a menor quantidade de resíduos comparada a mata, devese a parcial incorporação dos restos culturais. $\mathrm{O}$ sistema convencional obteve um teor de carbono residual inferior ao sistema de plantio direto (Figura 1), devido ao menor teor de resíduos culturais e o revolvimento destes (Figura 2).

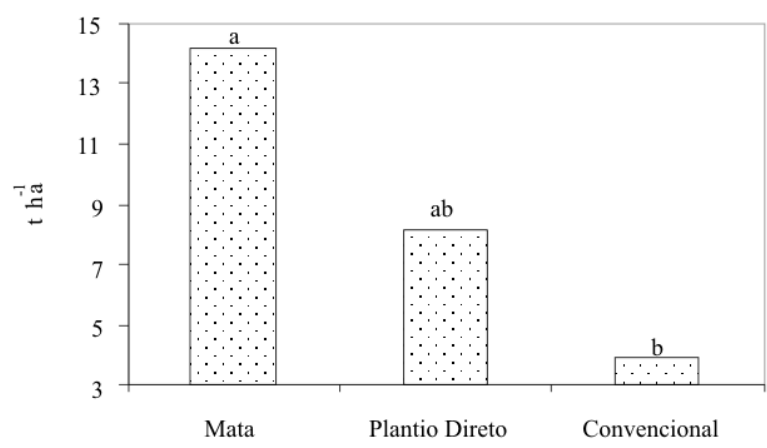

Figura 2. Serrapilheira e resíduos culturais dos sistemas plantio direto e convencional em $\mathrm{t} \mathrm{ha}^{-1}$ das áreas em estudo. Mesmas letras minúsculas não diferem entre si. (Teste de Tukey, $\mathrm{P} \leq 0,05$ ).

\section{Conclusão}

O restabelecimento químico de um sistema é lento e frágil, a mata apresentou bom equilíbrio entre os elementos. Os demais sistemas dependem da reposição química para atingirem o equilíbrio, devido à retirada através das culturas. Para o sistema de plantio direto notou-se uma grande deficiência em cálcio e excesso em hidrogênio. Quanto menor a mobilização e maior a manutenção dos resíduos vegetais sob o solo, maior será o teor de matéria orgânica e consequentemente de carbono residual $\left(\mathrm{C}_{\mathrm{NL}}\right)$ como apresentou a mata, seguida pelo sistema pastagem. O sistema convencional obteve um teor de carbono residual inferior ao sistema de plantio direto, devido ao menor teor de resíduos culturais e o revolvimento destes, ocasionando rápida oxidação da matéria orgânica.

\section{Referências}

ALBUQUERQUE, J. A.; ARGENTON, J.; BAYER, C.; WILDNER, L. P.; KUNTZE, M. A. G. Relação de atributos do solo com a agregação de um latossolo vermelho sob sistemas de preparo e plantas de verão para cobertura do solo. Revista Brasileira de Ciência do Solo, Viçosa, v. 29, n. 3, p. 415-424, 2005.

BAYER, C.; MIELNICZUK, J. Dinâmica e função da matéria orgânica. In: SANTOS, G. A.; CAMARGO, F. A. O. (Ed.). Matéria orgânica do solo: fundamentos e caracterização. Porto Alegre: Gênesis, 1999. p. 9-26.

BLAIR. G. J.; LEFROY, R. D. B.; LISLE, L. Soil carbon fractions based on their degree of oxidation, and development of a carbon management index for agricultural systems. Australian Journal Agricultural Research, Melbourne, v. 46, n. 7, p. 1459-1466, 1995.

CIOTTA, M. N. Componentes químicos do solo influenciados por sistemas de preparo e modos de calagem em experimento de longa duração. 2001. Dissertação. (Mestrado em Ciência do Solo) - Universidade do Estado de Santa Catarina, Florianópolis.

DIEKOW, J.; BAYER, C.; MARTIN NETO, L.; MIELNICZUK, J. Preparo do solo e o ciclo do carbono: preparo convencional, preparo mínimo e plantio direto. In: SIMPÓSIO SOBRE PLANTIO DIRETO E MEIO AMBIENTE: SEQÜESTRO DE CARBONO 
E QUALIDADE DA ÁGUA, 1., 2005, Foz do Iguaçu. Anais... Ponta Grossa: Federação Brasileira de Plantio Direto na Palha, 2005. p. 38-43.

EMPRESA BRASILEIRA DE PESQUISA AGROPECUÁRIA - EMBRAPA. Centro Nacional de Pesquisa de Solo. Sistema brasileiro de classificação de solos. Rio de Janeiro: Embrapa, 1999.

FERREIRA, D. F. Sisvar: versão 4.6. Lavras: DEX/ UFLA, 2003.

PAVAN, M. A.; BLOCH, M. F.; ZEMPULSKI, H. D.; MIYAZAWA, M.; ZOCOLER, D. C. Manual de análises químicas de solo e controle de qualidade. Londrina: IAPAR, 1992. (Circular, 76).
SHAMOOT, S.; MCDONALD, L.; BARTHOLOMEW, W. V. Rhizodeposition of organic matter debris in soil. Soil Science Society American Journal, Madison, v. 32, n. 6, p. 817-820, 1968.

SHANG, C.; TIESSEN, H. Organic matter lability in a tropical oxisol: evidence from shifting cultivation, chemical oxidation, particle size, density, and magnetic fractionations. Soil Science, Baltimore, v. 162, n. 11, p. 795-807, 1997.

SILVA, J. E.; LEMAINSKI, J.; RESCK, D. V. S. Perdas de matéria orgânica e suas relações com a capacidade de troca catiônica em solos da região de cerrados do oeste baiano. Revista Brasileira de Ciência do Solo, Viçosa, v. 18, n. 3, p. 541-547, 1994. 